\title{
Human Papillomavirus infection in men residing in Brazil, Mexico, and the USA
}

\author{
HPV Study group in men from Brazil, USA and Mexico.*
}

\section{Grupo de estudio de VPH en hombres de Brasil-Estados Unidos-México. Human Papillomavirus infection in men residing in Brazil, Mexico, and the USA. Salud Publica Mex 2008;50:408-4I8.}

\begin{abstract}
Objective. To assess Human Papillomavirus (HPV) type distribution among men ages 18 years and older recruited from three different countries utilizing a common protocol for sampling HPV detection, and to evaluate whether HPV detection differs by age and country. Material and Methods. The study protocol includes a pre-enrollment run-in visit, a baseline (enrollment) visit, and nine additional visits after enrollment scheduled six months apart. For this analysis, the first I 160 men who completed both the run-in and baseline visit were included.To maximize sampling and prevent fraying of applicators, three different applicators were utilized to sample the external genitalia of participants among different anatomic sites. These samples were later combined to form a single sample for the detection of HPV using polymerase chain reaction (PCR) for amplification of a fragment of the HPV LI gene. Results. Among I 160 men from Brazil, Mexico, and the United States (U.S.), overall HPV prevalence was 65.2\%; with $12.0 \%$ oncogenic types only, $20.7 \%$ non-oncogenic types only, $17.8 \%$ both oncogenic and non-oncogenic, and $14.7 \%$
\end{abstract}

\author{
Grupo de estudio deVPH en hombres \\ de Brasil-Estados Unidos-México. \\ Infección por Virus de Papiloma Humano \\ en hombres de Brasil, México y EUA.
}

Salud Publica Mex 2008;50:408-418.

\section{Resumen}

Objetivo. Evaluar la distribución tipo específica de infección porVirus del Papiloma Humano (VPH) entre hombres de 18 años o más de tres países con un protocolo común para el muestreo de la detección de VPH, y evaluar si la detección de VPH varía de acuerdo con la edad y el país. Material y métodos. El estudio incluye diversas etapas que inician con la identificación de hombres susceptibles, una medición basal (visita de enrolamiento) y nueve visitas adicionales programadas cada seis meses. En este artículo, se presenta el análisis de los primeros I 160 hombres que fueron incluídos en el estudio. Para maximizar la posibilidad de detección de VPH se utilizó un cepillo de dacrón que muestreó en forma combinada diferentes sitios anatómicos. Para la determinación de ADN deVPH se utilizó ión en cadena de polimerasa (PCR) por amplificación de un fragmento del gen deVPH LI. Resultados. Entre I 160 hombres de Brasil, México y EUA, la prevalencia global de VPH fue de $65.2 \%$, con solamente I $2 \%$

\footnotetext{
* Brazil: Meire Akemi Ishibashi,' Juliana A Antunes,' Maria Filomena C.Aoki,' Rossana Bombig Terreri,' Elisa Brito,' Roberto Carvalho Silva,' Ricardo F Cunha,' Fernanda F Da Silva,' Sandra de Araújo,' Maria Socorro F de Souza,' Vera Lucia de Souza, ' Rosangela Delgado,' Birgit Fietzek, ${ }^{2}$ Lenice Galan, ${ }^{2}$ José Carlos Gonçalves,' Raquel Hessel, ${ }^{2}$ Roberta Lima Bocalon,' Rosária M Martinez Otero,' Viviane Maria Relvas, ${ }^{2}$ Maria das Graças Ribeiro,' Luiz Roberto RibeiroVitor,' Conceição M Serrão Azevedo,' Luisa Villa, ${ }^{2}$ Rubens Yoshiaki Matsuo.'

USA: M Abrahamsen, ${ }^{3}$ ML Baggio, ${ }^{3}$ Kathy Eyring, ${ }^{3}$ Roberto Flores, ${ }^{3}$ Christine Gage, ${ }^{3}$ Anna R. Giuliano, ${ }^{3}$ Emily Jolles, ${ }^{3}$ Kayoko Kay, ${ }^{3}$ J-H Lee, ${ }^{3}$ M Papenfuss, ${ }^{3}$ Danelle Smith, ${ }^{3}$ Kyle Wolf.

Mexico: René de Jesús Alvear Vázques, ${ }^{4}$ Aurelio Cruz Valdez, ${ }^{5}$ Griselda Díaz García, ${ }^{4}$ Susana Gutiérrez Muñoz, ${ }^{5}$ María del Pilar Hernández Nevarez, ${ }^{5}$ Nadia Herrera Gutiérrez, ${ }_{4}^{4}$ Ana Laura Landa Vélez, ${ }^{4}$ Eduardo Lazcano-Ponce, ${ }^{5}$ Álvaro Pasáran García, ${ }^{4}$ Manuel Quiterio Trenado, ${ }^{4}$ Alfonso Rodríguez Cid, ${ }^{5}$ Alicia Rodríguez Galván, ${ }^{4}$ Oscar Rojas Juárez, ${ }^{4}$ Paola Román Rodríguez, ${ }^{4}$ Darío Antonio Salazar Sotelo, ${ }^{4}$ Jorge Salmerón Castro. ${ }^{4}$
}

(I) Centro de Referência e Treinamento em DST/Aids (CRT-DST/Aids). São Paulo, Brazi

(2) Ludwig Institute for Cancer Research. São Paulo, Brazil.

(3) H. Lee Moffitt Cancer Center and Research Institute. Tampa, Florida.

(4) Unidad de Investigación Epidemiológica y en Servicios de Salud, Instituto Mexicano del Seguro Social. Cuernavaca, México

(5) Instituto Nacional de Salud Pública. Cuernavaca, México

Received on: April 7,2008 - Accepted on: July 10,2008

Address reprint requests to: Dr.Anna R. Giuliano, H. Lee Moffitt Cancer Center and Research Institute, I2902 Magnolia Drive MRC 2067D, Tampa, FL 336I2. E-mail:Anna.Giuliano@moffitt.org Dr. Luisa Villa. Ludwig Institute for Cancer Research, Hospital Alemão Oswaldo Cruz R. João Julião 245 0I323-903 São Paulo, SP, Brazil. E-mail: Ilvilla@ludwig.org.b Dr. Eduardo Lazcano-Ponce. Instituto Nacional de Salud Pública. Av. Universidad 655, col. Sta. María Ahuacatitlán. 62508 Cuernavaca, Morelos México. E-mail: elazcano@insp.mx 
unclassified infections. Multiple HPV types were detected in $25.7 \%$ of study participants. HPV prevalence was higher in Brazil $(72.3 \%)$ than in the U.S. (6I.3\%) and Mexico (6I.9\%). HPV I 6 (6.5\%), $5 \mathrm{I}$ (6.5\%), and 59 (5.3\%) were the most commonly detected oncogenic infections, and HPV 84 (7.7\%), $62(7.3 \%)$, and $6(6.6 \%)$ were the most commonly detected non-oncogenic infections. Overall HPV prevalence was not associated with age. However, significant associations with age were observed when specific categories of oncogenic, non-oncogenic, and unclassified HPV infections were considered. Conclusions. Studies of HPV type distribution among a broad age range of men from multiple countries is needed to fill the information gap internationally with respect to our knowledge of HPV infection in men.

Key words: HPV; males; multicenter study; sexual behavior de tipos oncogénicos, $20.7 \%$ de tipos deVPH no oncogénicos, $17.8 \%$ de muestras positivas a tipos oncogénicos y no oncogénicos; $y$ finalmente $14.7 \%$ de infecciones no clasificadas. Múltiples tipos de VPH fueron detectados en $25.7 \%$ de los participantes en el estudio. La prevalencia de VPH fue más alta en Brasil (72.3\%), comparada con la observada en EUA (61.3\%) y México (6I.9\%). Los tipos de VPH I6 (6.5\%), 51 (6.5\%) y 59 (5.3\%) fueron los más comúnmente observados con poder oncogénico. EIVPH 84 (7.7\%), 62 (7.3\%) y 6 (6.6\%) fueron las infecciones no oncogénicas más comunes. Conclusiones. Son necesarios estudios de la distribución deVPH en un amplio margen de edad entre hombres de múltiples países, para establecer con mayor precisión, el conocimiento de la historia natural de la infección porVPH en hombres.

Palabras clave: VPH; hombres; estudio multicéntrico; conducta sexual
$\mathrm{M}$ ale HPV infection significantly contributes to infection and subsequent cervical disease in women. ${ }^{1-4}$ Case-control studies of women with cervical cancer and their husbands have demonstrated that men's sexual behavior affects women's risk of cervical neoplasia, even when controlling for female sexual activity. ${ }^{1-7}$ In areas with a high incidence of cervical cancer, men's sexual behavior is in itself a risk factor for cervical neoplasia. ${ }^{7}$ More recently we have recognized that HPV contributes to men's burden of diseases such as anal, penile, and oropharyngeal cancers and genital warts. ${ }^{8}$ A growing interest in understanding HPV infection in men necessitates the characterization of these infections in terms of type distribution across countries. Unfortunately, there is a paucity of studies that can shed light on male HPV type distribution in any one country or across countries.

Few HPV studies have been conducted among heterosexual men, with only a subset reporting HPV type distribution and age-specific prevalence estimates. ${ }^{9}$ No studies to date have included a broad age range of men from multiple countries, which limits our ability to draw conclusions about differences in HPV type distribution among men. For example, observed differences in HPV type distribution in men may be due to differences in tissue tropism for particular HPV types due to anatomic site sampled. Alternatively, they may be due to differences in populations studied, similar to what we understand for cervical HPV. ${ }^{10}$ This information is needed to inform future prevention efforts that may influence infection and disease reduction in men and consequently in women. The purpose of the current study was to assess HPV type-distribution among men ages 18 years and older recruited from three different countries utilizing a common protocol for sampling and HPV detection, and to evaluate whether HPV detection differs by age and country.

\section{Materials and methods}

Men enrolled from March 2005 to December 2006 in the ongoing HPV in Men (HIM) Study were included in this analysis. Participants were recruited from Sao Paulo, Brazil; Cuernavaca, Mexico; Tampa, Florida; and surrounding areas. To encourage compliance with follow-up, men received compensation or food or transportation reimbursement for their participation. Prior to study initiation, the Human Subjects Committees of the University of South Florida, the CRT-DST/Aids, Brazil, and the National Institute of Public Health of Mexico approved all study procedures. All participants gave written informed consent.

Population. The study population consisted of men who met the following eligibility criteria: a) ages 18-70 years; b) residents of one of three sites -Sao Paulo, Brazil; the state of Morelos, Mexico; or southern Florida, U.S.; c) report no prior diagnosis of penile or anal cancers; $d$ ) have never been diagnosed with genital or anal warts; e) currently report no symptoms of a sexually transmitted infection (STI) or treatment for an STI; f) not participating in an HPV vaccine study; g) no history of HIV or AIDS; h) no history of imprisonment, homelessness, or drug treatment during the past six months; and i) willing to comply with ten scheduled visits every six 
months for four years with no plans to relocate within the next four years.

Men were recruited from three different population sources-general population, universities, and organized health care systems (Mexico only)- to increase access to men with a broad range of ages, sexual behaviors, and HPV risk. In Brazil, men were recruited from the general population at a facility for urogenital care (Centro de Referencia e Tratamento de Doencas Sexualmente Transmissiveis e AIDS) and through general media advertising. Men presenting for non-STI related conditions were enrolled in the present study. In addition, the spouses and partners of women participating in a large cohort study of the natural history of HPV infection and risk of cervical neoplasia conducted in Sao Paulo since 1993 were also recruited. At the Cuernavaca, Mexico site, the underlying population was employees and beneficiaries of the Instituto Mexicano de Seguro Social (IMSS), factory employees, and officials of the Mexican army that are permanently assigned to this geographic area. In the U.S., the underlying population was from the University of South Florida and the greater Tampa metropolitan area. Flyers and posters were distributed throughout the campus and community, and we administered monthly educational presentations. In addition, men from the broader Tampa Bay, FL, community were recruited through the mail and media using brochures and flyers as well as advertisements in local and university papers.

\section{Study Protocol}

The HIM Study protocol includes a pre-enrollment runin visit, a baseline (enrollment) visit, and nine additional visits after enrollment scheduled six months apart. For this analysis, the first 1160 men who completed both the run-in and baseline visit were included.

Risk Factor Questionnaire: An extensive sexual history and health questionnaire given at enrollment assessed socio-demographic characteristics, sexual and contraceptive history, condom use practices, alcohol and tobacco use, and history of abnormal Pap smears in female partners. The questionnaire required roughly 20 minutes to complete and was administered using Computer-Assisted Self-Interviewing (CASI).

HPV Penile and Scrotal Sampling: To maximize sampling and prevent fraying of applicators, three different prewetted Dacron applicators were utilized to sample the external genitalia of participants, and were later combined to form a single sample for the detection of HPV. This method has been previously shown to maximize $\mathrm{HPV}$ detection among men and to result in reproducible genital HPV detection in men. ${ }^{11,12}$ The study clinician at each site first swept $360^{\circ}$ around the coronal sulcus and then another $360^{\circ}$ around the glans penis and placed this swab into a separate collection vial with STM labeled by anatomic site. A second wet swab was used to sample the entire skin surface of each of the quadrants of the shaft of the penis (left and right ventral, and left and right dorsal) and placed into a vial labeled "shaft." A third Dacron swab moistened with normal saline was utilized for scrotum sampling and stored in $450 \mu \mathrm{l} \mathrm{STM}$. The Dacron swabs used for each anatomic site were placed in a bar-coded 20-ml Falcon tube and sent to the Moffit Cancer Center for HPV testing. All HPV samples were stored at $-70 \mathrm{o} C$ until PCR analyses and genotyping were conducted. Prior to DNA extraction, the three samples of normal anogenital skin were combined to produce one DNA extract per participant clinic visit.

\section{HPV Analyses}

HPV testing of collected material was conducted using polymerase chain reaction (PCR) for amplification of a fragment of the HPV L1 gene..$^{13}$ DNA extraction was performed using the QIAamp DNA Mini Kit (QIAGEN, Valencia, CA) according to the instructions from the manufacturer. Briefly, 200 $\mu \mathrm{l}$ aliquots of clinical material were digested with $20 \mu \mathrm{l}$ proteinase K solution for $1 \mathrm{hr}$ at $65^{\circ} \mathrm{C}$, followed by $200 \mu \mathrm{l}$ of lysis buffer.

Specimens were tested for the presence of HPV by amplifying $50 \mu$ of the DNA extracts using the Linear Array HPV genotyping test following the instructions from the manufacturer (Roche Diagnostics, Indianapolis, IN). Samples were amplified using Perkin-Elmer GeneAmp PCR System 9700 as directed by the linear array protocol. HPV genotyping was conducted on all samples regardless of HPV PCR result. ${ }^{14} \beta$-globin was detected in $99.7 \%$ of samples tested (1156/1160). Samples that amplified HPV on PCR but did not hybridize with a specific HPV type on genotype were categorized as unclassified infections. As it is unclear whether these are HPV infections or co-amplification of other genes, we report the prevalence of these products separately in tables. The following $13 \mathrm{HPV}$ types were categorized as oncogenic: $16,18,31,33,35,39,45,51,52,56,58,59$, and $66 .{ }^{15}$ The other (non-oncogenic) types detected with the Linear Array methodology of Roche were 6, 11, 26, $40,42,44,53,54,61,62,64,67,68,69,70,71,72,73,81$, $82,83,84$, IS39, and CP6108.

All unclassified samples were characterized by direct sequencing of a fragment of the L1 gene. Amplicons for sequencing were generated by Nested PCR using the PGMY09/11 13 and GP5/6+ primers $^{16}$ in a $50 \mu 1$ reaction. In brief, $1 \mu$ of DNA isolated from the biological specimen 
was used first in the PGMY09/11 reaction; these products were diluted $1 / 50$ prior to use in the GP5/6+ reaction, with standard reagents and reaction conditions, except for the use of a lower concentration of GP5/6+ primers $(0.1 \mu \mathrm{M})$. After visualization of PCR products by gel electrophoresis, $1 \mu \mathrm{l}$ of the nested-PCR products of about 150 bp were submitted to sequencing using GP6+ primer. Uncoupled dyes were eliminated from samples by ethanol precipitation prior to sequencing on an Applied Biosystems 3130xl Genetic Analyzer apparatus using the "BigDye Terminator v3.1 Sequencing Kit" according to the manufacturer protocols. Sequence identity was determined by comparison with the "BlastN database" of the NCBI, and those with scores greater than "e-15" were conclusively typed.

\section{Statistical Analysis}

A participant was considered positive for 'any HPV' if he tested HPV positive by PCR or by genotyping. The category of 'any oncogenic type' included those who were positive for only oncogenic genotypes and those who were positive for both oncogenic and nononcogenic types. Only single or multiple infections with non-oncogenic HPV types were classified as "any non-oncogenic type". Samples testing positive for HPV by PCR but negative for all of the 37 genotypes were labeled "unclassified."

Differences in the distribution of demographic characteristics and HPV prevalence were explored by country and by age, and associations were tested with Pearson's Chi-square test. Participants were given the option of refusing to answer each of the questions on the Web-based survey and these refusals were treated as missing observations. Associations between types of HPV infections and country were evaluated using Pearson's Chi-square test, and the raw p-values were adjusted for multiple comparisons using the step-down Bonferroni approach. ${ }^{17}$ Differences in the distribution of HPV type 6, 11, 16, and 18 by country were evaluated using Fisher's exact test.

\section{Results}

A total of 1160 men completing an enrollment visit (362 from Mexico, 382 from Brazil, and 416 from the U.S.) were included in this analysis. Forty-nine percent of participants were ages $18-29$ yrs, $41.4 \%$ were ages $30-44$ yrs, and 9.6\% were ages $45-70$ yrs (Table I). The majority of study participants were non-white, with $33.0 \%$ reporting mixed race and $41.9 \%$ reporting Hispanic ethnicity. Approximately $45 \%$ of participants were either married or cohabiting, and $46.9 \%$ reported being single or never married. The majority (53.1\%) of participants had completed 13 or more years of education. Overall, $8.9 \%$ of participants reported never having had sexual intercourse with a female. The majority of men reported 1 to 9 female sexual partners in his lifetime. Circumcision was common in the US (83.2\%) and rare in Mexico $(14.1 \%)$ and Brazil (14.9\%). Statistically significant differences were observed in the distribution of all study characteristics evaluated by country.

Table II presents HPV prevalence by country for oncogenic, non-oncogenic, unclassified, and multiple infections and compares prevalence across countries. Overall HPV prevalence in the study population was $65.2 \%$. Twelve percent of infections were with oncogenic HPV types only, 20.7\% with non-oncogenic HPV types only, $17.8 \%$ were mixed oncogenic and non-oncogenic, and $14.7 \%$ were with only unclassified HPV infections. Multiple HPV types were detected in $25.7 \%$ of study participants. Prevalence of any HPV infection was highest in Brazil (72.3\%) and lowest in the U.S. (61.3\%) and Mexico $(61.9 \%)(p=0.03)$. A similar trend in prevalence across countries was observed for oncogenic HPV $(p=0.002)$, non-oncogenic HPV $(p<0.0001)$, and multiple HPV infections $(p<0.0001)$. Unclassified infections were highest in the US $(20.0 \%)$, with lower prevalence observed in Mexico (13.5\%) and Brazil $(10.0 \%)$ ( $p=0.002)$.

Across the three international populations, HPV 16 $(6.5 \%)$ and $51(6.5 \%)$ were the most commonly detected oncogenic infections, followed by HPV types 59 (5.3\%), $66(5.0 \%), 39(3.6 \%)$, and 52 (3.5\%) (Table III). Among the non-oncogenic infections, HPV type 84 was most commonly detected (7.7\%), followed by HPV types 62 (7.3\%), 6 (6.6\%), and CP6108 (5.7\%). HPV type distribution varied across countries. For example, in Brazil and the U.S., HPV 16 was the most common oncogenic infection detected, whereas in Mexico HPV 59 was the most common type. Among the non-oncogenic infections, HPV 62 was the most commonly detected in Brazil, and HPV 84 was the most commonly detected type in Mexico and the U.S. Prevalence of the current prophylactic HPV vaccine types were: $5.5 \%-7.1 \%$ for HPV 16, 0.5\%-3.1\% for HPV 18, 4.1\%-9.4\% for HPV 6, and $0.0 \%-2.9 \%$ for HPV 11. Significant differences in the prevalence of HPV types 6, 11, and 18 were observed by country, with Brazil having the highest prevalence of these infections (all $p<0.01$ ).

Results from sequencing "unclassified infection" specimens demonstrated that most unclassified infections probably represent spurious PCR products. We were able to re-amplify, with a nested PCR protocol aiming a smaller PCR fragment (150bp), only 60 of the 204 specimens and were able to generate readable sequences from 41 of these. Of those specimens that generated 
Table I

SOCIODEMOGRAPHIC CHARACTERISTICS OF HPV IN MEN STUDY PARTICIPANTS BY COUNTRY*

\begin{tabular}{|c|c|c|c|c|c|c|c|c|}
\hline \multirow[b]{3}{*}{ Age } & \multicolumn{2}{|c|}{$\begin{array}{l}\text { Sao Paulo, Brazil } \\
\qquad(N=382)\end{array}$} & \multicolumn{2}{|c|}{$\begin{array}{c}\text { Cuernavaca, México } \\
\quad(N=362)\end{array}$} & \multicolumn{2}{|c|}{$\begin{array}{l}\text { Tampa, US } \\
(N=416)\end{array}$} & \multicolumn{2}{|c|}{$\begin{array}{c}\text { Total } \\
(N=1 / 60)\end{array}$} \\
\hline & $n$ & $\%$ & $n$ & $\%$ & $\frac{1}{n}$ & $\%$ & $n$ & $\%$ \\
\hline & & & & & & & & \\
\hline $18-19$ & 12 & 3.1 & 15 & 4.1 & 95 & 22.8 & 122 & 10.5 \\
\hline $20-24$ & 56 & 14.7 & 51 & 14.1 & 155 & 37.3 & 262 & 22.6 \\
\hline $25-29$ & 67 & 17.5 & 75 & 20.7 & 43 & 10.3 & 185 & 16.0 \\
\hline $30-34$ & 75 & 19.6 & 69 & 19.1 & 30 & 7.2 & 174 & 15.0 \\
\hline $35-39$ & 51 & 13.4 & 66 & 18.2 & 34 & 8.2 & $15 \mid$ & 13.0 \\
\hline $40-44$ & 65 & 17.0 & 64 & 17.7 & 26 & 6.3 & 155 & 13.4 \\
\hline $45-70$ & 56 & 14.7 & 22 & 6.1 & 33 & 7.9 & III & 9.6 \\
\hline \multicolumn{9}{|l|}{ Race } \\
\hline White & 229 & 60.6 & 13 & 3.6 & 303 & 73.2 & 545 & 47.3 \\
\hline Black & 115 & 30.4 & I & 1.3 & 52 & 12.6 & 168 & 14.6 \\
\hline Asian/Pacific Islander & 5 & 1.4 & 0 & 0.0 & 21 & 5.1 & 26 & 2.3 \\
\hline American Indian & 22 & 5.8 & 0 & 0.0 & 0 & 0.0 & 22 & 1.9 \\
\hline Mixed & 0 & 0.0 & 343 & 95.0 & 37 & 8.9 & 380 & 33.0 \\
\hline Unknown & 7 & 1.9 & 4 & I.I & I & 0.2 & 12 & 1.0 \\
\hline \multicolumn{9}{|l|}{ Ethnicity } \\
\hline Hispanic & 66 & 17.9 & 361 & 100.0 & 52 & 12.6 & 479 & 41.9 \\
\hline Non-Hispanic & 303 & 82.1 & 0 & 0.0 & 362 & 87.4 & 665 & 58.1 \\
\hline \multicolumn{9}{|l|}{ Marital status } \\
\hline Single, never married & 148 & 39.3 & 91 & 25.2 & 300 & 72.8 & 539 & 46.9 \\
\hline Married & 118 & 31.3 & 208 & 57.6 & 61 & 14.8 & 387 & 33.6 \\
\hline Cohabiting & 71 & 18.8 & 45 & 12.5 & 16 & 3.9 & 132 & 11.5 \\
\hline Divorced/separated/widower & 40 & 10.6 & 17 & 4.7 & 35 & 8.5 & 92 & 8.0 \\
\hline \multicolumn{9}{|l|}{ Education } \\
\hline Less than 12 years & 122 & 32.3 & 128 & 35.6 & 6 & 1.5 & 256 & 22.3 \\
\hline 12 years & 144 & 38.1 & 82 & 22.8 & 58 & 14.1 & 284 & 24.7 \\
\hline $13-16$ years & 102 & 27.0 & 135 & 37.5 & 310 & 75.2 & 547 & 47.6 \\
\hline 17 years or more & 10 & 2.7 & 15 & 4.2 & 38 & 9.2 & 63 & 5.5 \\
\hline \multicolumn{9}{|l|}{ Lifetime number female partners } \\
\hline None & 40 & 11.9 & 27 & 7.7 & 29 & 7.3 & 96 & 8.9 \\
\hline I & 23 & 6.9 & 22 & 6.3 & 45 & 11.3 & 90 & 8.3 \\
\hline $2-9$ & 103 & 30.8 & 214 & 61.0 & $17 \mid$ & 42.9 & 488 & 45.0 \\
\hline $10-19$ & 63 & 18.8 & 46 & 13.1 & 66 & 16.5 & 175 & 16.1 \\
\hline $20-49$ & 80 & 23.9 & 34 & 9.7 & 61 & 15.3 & 175 & 16.1 \\
\hline $50-1000$ & 26 & 7.8 & 8 & 2.3 & 27 & 6.8 & 61 & 5.6 \\
\hline Circumcised & 57 & 14.9 & 51 & 14.1 & 346 & 83.2 & 454 & 39.1 \\
\hline \multicolumn{9}{|c|}{ Condom with vaginal sex in past 3 mos. } \\
\hline Always & 76 & 20.3 & 48 & 13.4 & 93 & 22.6 & 217 & 19.0 \\
\hline Sometimes & 117 & 31.3 & 97 & 27.1 & 138 & 33.6 & 352 & 30.8 \\
\hline Never & 99 & 26.5 & 170 & 47.5 & 98 & 23,8 & 367 & 32.1 \\
\hline No vaginal & 82 & 21.9 & 43 & 12.0 & 82 & 20.0 & 207 & 18.1 \\
\hline \multicolumn{9}{|c|}{ Sex in past 3 months ever had partner with abnormal pap } \\
\hline Yes & 50 & 13.3 & 64 & 17.7 & 51 & 12.3 & 165 & 14.3 \\
\hline No & 197 & 52.4 & 202 & 56.0 & 213 & 51.5 & 612 & 53.2 \\
\hline Don't know & 127 & 34.3 & 95 & 26.3 & 150 & 36.2 & 374 & 32.5 \\
\hline \multicolumn{9}{|l|}{ Lifetime number of male partners } \\
\hline None & 253 & 70.9 & 319 & 91.4 & 371 & 92.1 & 943 & 85.0 \\
\hline$<5$ & 72 & 20.2 & 30 & 8.6 & 30 & 7.4 & 132 & 11.9 \\
\hline$>=5$ & 32 & 9.0 & 0 & 0.0 & 2 & 0.5 & 34 & 3.1 \\
\hline Never had sex with male or female & 20 & 5.4 & 24 & 7.0 & 17 & 4.6 & 61 & 5.6 \\
\hline Current Smoker & 78 & 20.6 & 140 & 38.8 & 69 & 16.7 & 287 & 24.9 \\
\hline \multicolumn{9}{|c|}{ Number of alcoholic drinks in past I mo. } \\
\hline None & 101 & 26.4 & 82 & 22.7 & 64 & 15.4 & 247 & 21.3 \\
\hline$<=30$ & 142 & 37.2 & 170 & 47.0 & 167 & 40.1 & 479 & 41.3 \\
\hline $\mid>30$ & 139 & 36.4 & 110 & 30.4 & 185 & 44.5 & 434 & 37.4 \\
\hline
\end{tabular}

* Note: Distribution of all variables examined differed significantly by country, $p<0.000$ I 
Table II

SUMMARY RESULTS FOR GROUPED HPV TYPE DISTRIBUTION BY COUNTRY AT ENROLLMENT

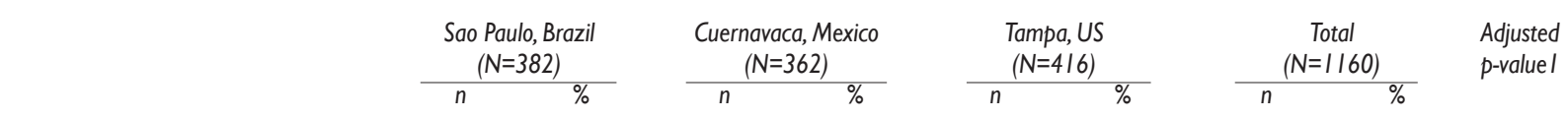

\begin{tabular}{lrrrrrrrrr} 
Any HPV type & 276 & 72.3 & 224 & 61.9 & 255 & 61.3 & 755 & 65.2 & $\mathbf{0 . 0 3}$ \\
\hline Any oncogenic type & 138 & 36.1 & 110 & 30.4 & 97 & 23.3 & 345 & 29.7 & 0.002 \\
\hline Oncogenic type(s) only $\ddagger$ & 45 & 11.8 & 48 & 13.3 & 46 & 11.1 & 139 & 12.0 & 0.6 \\
\hline Any non-oncogenic type & 193 & 50.5 & 127 & 35.1 & 126 & 30.3 & 446 & 38.5 & $<0.000 I$ \\
\hline Non-oncogenic type(s) only $\ddagger$ & 100 & 26.2 & 65 & 18.0 & 75 & 18.0 & 240 & 20.7 & 0.02 \\
\hline Both Onco- \& non-oncogenic ${ }^{\ddagger}$ & 93 & 24.4 & 62 & 17.1 & 51 & 12.3 & 206 & 17.8 & $<.0001$ \\
\hline Unclassified type(s) only $\ddagger .8$ & 38 & 10.0 & 49 & 13.5 & 83 & 20.0 & 170 & 14.7 & 0.002 \\
\hline Multiple types & 138 & 36.2 & 86 & 23.8 & 74 & 17.8 & 298 & 25.7 & $<0.0001$
\end{tabular}

* Adjusted by Holm's method: Step-down Bonferroni approach (I7)

$\ddagger$ The $\mathrm{n}$ and percent in these four rows sum to the top row (categories are complete and mutually exclusive)

$\S$ Samples were HPV positive by PCR but not by genotyping

readable sequences, $41.2 \%$ contained cutaneous $\mathrm{HPV}$ types (HPV types 2, 3, 12, 17, 22, 23, 62, 69, 74, 87, 91, 107), $39 \%$ had very low copy number anogenital types (HPV 6, 33, 39, 42, 44, 52, 56, 59, 84), and 1\% contained novel HPV types.

No significant differences in overall HPV prevalence were observed by age, regardless of country examined (table IV). Similarly, there was no clear association with age when unclassified HPV infections were eliminated from the analysis. However, when men ages 18-19 years old were compared to all other age groups, prevalence estimates were significantly lower among the younger men $(27.9 \%$ vs. $50.4 \%$, data not shown). When HPV infections were grouped by oncogenic potential and examined by age, across the three countries, we observed a significant association between age and oncogenic HPV infections (figure 1). Oncogenic infections increased with age between 18 and 34 years (peak prevalence of $40.8 \%$ at ages $30-34$ years) and decreased with age from age 35 to 70 years $(p=0.001)$. Non-oncogenic infections significantly increased with age with a low prevalence of $9.8 \%$ among $18-19$ year olds and a peak prevalence of $27.9 \%$ among men ages $45-70$ years $(p=0.002)$. Unclassified infections significantly decreased with age $(p=0.001)$.

\section{Discussion}

In this manuscript we present HPV type distribution by country and associations with HPV infections and age. A common protocol was utilized in clinics in the US, Mexico, and Brazil, allowing for direct comparisons of HPV prevalence. This is the first international comparison of HPV type distribution across 37 genotypes in a general population of men. Among men enrolled in the HIM Study, overall HPV prevalence based on genotyping was $50.5 \%$, with $62.3 \%$ in Brazil, $48.4 \%$ in Mexico, and $41.3 \%$ in the US. Approximately $15 \%$ of men were positive for unclassified HPV types, defined as samples positive by PCR but negative based on genotyping by hybridization against 37 individual HPV types. These genotype prevalence estimates are higher than previously reported in men. ${ }^{9}$ This may be a result of more complete genital sampling in men than previously conducted and application of more sensitive HPV detection methodology with genotyping of 37 different HPV types. ${ }^{18}$ Due to these differences, as well as inconsistencies in the HPV types considered oncogenic (13 or more HPV types) in previous publications, it is difficult to make direct comparisons of HPV prevalence across studies. This problem is accentuated when examining infection with any HPV and grouped infections such as oncogenic or non-oncogenic HPV prevalence.

Prophylactic HPV vaccine types 6 and 11 (nononcogenic types) and 16 and 18 (oncogenic types) were detected in $14.7 \%$ of participants; HPV 6 was detected in $6.6 \%$, HPV 11 in $1.5 \%$, HPV 16 in $6.5 \%$, and HPV 18 in $1.7 \%$ of HIM Study participants. Significant differences in the prevalence of vaccine related HPV infections were observed by country for HPV types 6, 11, and 18 , although there was no significant difference in the prevalence of HPV 16. This trend mirrored the observed overall HPV prevalence differences by country: Brazil had the highest prevalence overall as well as for indi- 
Table III

TYPE-SPECIFIC HPV INFECTION DISTRIBUTION BY COUNTRY AT ENROLLMENT

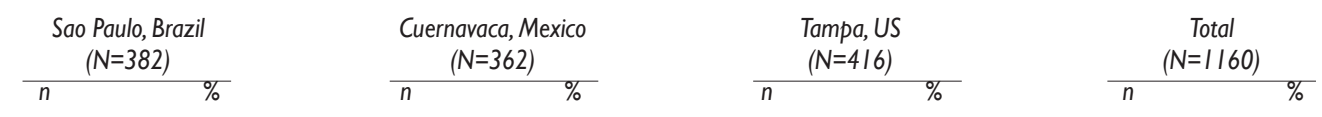

Oncogenic types

\begin{tabular}{|c|c|c|c|c|c|c|c|c|}
\hline 16 & 27 & 7.1 & 20 & 5.5 & 28 & 6.7 & 75 & 6.5 \\
\hline $18 *$ & 12 & 3.1 & 6 & 1.7 & 2 & 0.5 & 20 & 1.7 \\
\hline 31 & 7 & 4.2 & 5 & I.4 & 2 & 0.5 & 14 & 1.5 \\
\hline 33 & I & 0.6 & 1 & 0.3 & 0 & 0.0 & 2 & 0.2 \\
\hline 35 & 13 & 3.4 & 3 & 0.8 & 5 & 1.2 & 21 & 1.8 \\
\hline 39 & 12 & 3.1 & 18 & 5.0 & 12 & 2.9 & 42 & 3.6 \\
\hline 45 & 11 & 2.9 & I & 0.3 & I & 0.2 & 13 & I.I \\
\hline 51 & 11 & 6.6 & 24 & 6.6 & 26 & 6.3 & 61 & 6.5 \\
\hline 52 & 15 & 3.9 & 13 & 3.6 & 13 & 3.1 & $4 I$ & 3.5 \\
\hline 56 & 12 & 3.1 & 7 & 1.9 & 5 & 1.2 & 24 & 2.1 \\
\hline 58 & 15 & 3.9 & 7 & 1.9 & 5 & 1.2 & 27 & 2.3 \\
\hline 59 & 19 & 5.0 & 26 & 7.2 & 17 & 4.1 & 61 & 5.3 \\
\hline 66 & 25 & 6.5 & 15 & 4.1 & 18 & 4.3 & 58 & 5.0 \\
\hline
\end{tabular}

Non-oncogenic types

\begin{tabular}{|c|c|c|c|c|c|c|c|c|}
\hline $6 *$ & 36 & 9.4 & 15 & 4.1 & 26 & 6.3 & 77 & 6.6 \\
\hline II * & 11 & 2.9 & 6 & 1.7 & 0 & 0.0 & 17 & 1.5 \\
\hline 26 & 3 & .8 & 0 & 0.0 & I & 0.2 & 4 & 0.3 \\
\hline 40 & 6 & 1.6 & 4 & I.I & 5 & 1.2 & 15 & 1.3 \\
\hline 42 & 7 & 1.8 & 3 & 0.8 & 4 & 1.0 & 14 & 1.2 \\
\hline 44 & 10 & 2.6 & 7 & 1.9 & 6 & I.4 & 23 & 2.0 \\
\hline 53 & 29 & 7.6 & 8 & 2.2 & 19 & 4.6 & 56 & 4.8 \\
\hline 54 & 12 & 3.1 & 11 & 3.0 & 8 & 1.9 & 31 & 2.7 \\
\hline 61 & 35 & 9.2 & 16 & 4.4 & 8 & 1.9 & 59 & 5.1 \\
\hline 62 & 41 & 10.7 & 20 & 5.5 & 24 & 5.8 & 85 & 7.3 \\
\hline 64 & 0 & 0.0 & 1 & 0.3 & 0 & 0.0 & I & 0.1 \\
\hline 67 & 2 & 0.5 & I & 0.3 & I & 0.2 & 4 & 0.3 \\
\hline 68 & 10 & 2.6 & 12 & 3.3 & 9 & 2.2 & 31 & 2.7 \\
\hline 69 & 2 & 0.5 & 0 & 0.0 & I & 0.2 & 3 & 0.3 \\
\hline 70 & 14 & 3.7 & 7 & 1.9 & 5 & 1.2 & 26 & 2.2 \\
\hline 71 & 4 & I.I & 9 & 2.5 & 0 & 0.0 & 13 & I.I \\
\hline 72 & 8 & 2.1 & 3 & 0.8 & 3 & 0.7 & 14 & 1.2 \\
\hline 73 & 13 & 3.4 & 2 & 0.6 & 0 & 0.0 & 15 & 1.3 \\
\hline 81 & 23 & 6.0 & 13 & 3.6 & 6 & 1.4 & 42 & 3.6 \\
\hline 82 & 0 & 0.0 & 2 & 0.6 & 6 & I.4 & 8 & 0.7 \\
\hline 83 & 11 & 2.9 & 12 & 3.3 & 11 & 2.6 & 34 & 2.9 \\
\hline 84 & 35 & 9.2 & 24 & 6.6 & 30 & 7.2 & 89 & 7.7 \\
\hline CP6I08 & 31 & 8.1 & 16 & 4.4 & 19 & 4.6 & 66 & 5.7 \\
\hline IS39 & 3 & 0.8 & 0 & 0.0 & 2 & 0.5 & 5 & 0.4 \\
\hline
\end{tabular}

Note: Due to infection with multiple HPV types, the percentage of infections exceeds $100 \%$.

* HPV type distribution significantly different by region $(p<0.010)$ 


\section{Table IV}

Age-SPECIFIC PREVAlenCe of ANy tyPe HPV by COUNTRY AT ENROLLMENT

\begin{tabular}{|c|c|c|c|c|c|c|c|c|}
\hline & \multicolumn{2}{|c|}{$\begin{array}{l}\text { Sao Paulo, Brazil } \\
\quad(N=382)\end{array}$} & \multicolumn{2}{|c|}{$\begin{array}{c}\text { Cuernavaca, Mexico } \\
(N=362)\end{array}$} & \multicolumn{2}{|c|}{$\begin{array}{l}\text { Tampa, US } \\
(N=416)\end{array}$} & \multicolumn{2}{|c|}{$\begin{array}{c}\text { Total } \\
(N=\mid / 60)\end{array}$} \\
\hline & $n$ & $\%$ & $n$ & $\%$ & $n$ & $\%$ & $n$ & $\%$ \\
\hline \multicolumn{9}{|l|}{ Age } \\
\hline $18-19$ & 10 & 83.3 & 9 & 60.0 & 49 & 51.6 & 68 & 55.7 \\
\hline $20-24$ & 44 & 78.6 & 30 & 58.8 & 95 & 61.3 & 169 & 64.5 \\
\hline $25-29$ & 47 & 70.2 & 46 & 61.3 & 30 & 69.8 & 123 & 66.5 \\
\hline $30-34$ & 55 & 73.3 & 47 & 68.1 & 22 & 73.3 & 124 & 71.3 \\
\hline $35-39$ & 38 & 74.5 & 36 & 54.6 & 22 & 64.7 & 96 & 63.6 \\
\hline $40-44$ & 46 & 70.8 & 44 & 68.8 & 17 & 65.4 & 107 & 69.0 \\
\hline $45-70$ & 36 & 64.3 & 12 & 54.6 & 20 & 60.6 & 68 & 61.3 \\
\hline$p$-value & & 0.7 & & 0.6 & & 0.3 & & 0.1 \\
\hline
\end{tabular}

vidual vaccine related HPV types.

To our knowledge, only two prior studies examined HPV prevalence among men in Brazil. One study was a small cross-sectional study, ${ }^{19}$ and in the other all men were husbands of wives enrolled in a cervical cancer case-control study. ${ }^{20}$ Among husbands of controls, HPV prevalence was approximately $40 \%$ and approximately $16 \%$ were HPV 16 positive. The overall HPV prevalence estimates in that study were lower than the Brazil arm of the HIM Study $(72.3 \%)$, although the HPV 16 prevalence detected was higher than the Brazil cohort (7.1\%).

Three previous studies estimated HPV prevalence among men residing in Mexico. Excluding unclassified infections, prevalence estimates were $44.6 \%{ }^{21}$ and $42.7 \% 22$ in each of the first two studies and were similar to those observed in the Mexican arm of the HIM Study. In the third study, conducted among men attending vasectomy clinics nationally, the prevalence estimate was considerably lower, at $8.7 \% .{ }^{23}$ Prevalence of any oncogenic HPV infection (14 HPV types) in the cross-sectional study of students and factory workers was $19.8 \%$, a value lower than the $30.4 \%$ observed in the current study. ${ }^{22}$ Prevalence of type-specific infection was not reported in this study. Interestingly, among Mexican military men enrolled in a prospective study, ${ }^{21}$ prevalence of any oncogenic infection at baseline was 34.8\% (16 HPV types). Prevalence of HPV types 6, 11, 16, and 18 was $4.3 \%, 3.4 \%, 6.0 \%$, and $3.7 \%$, respectively, values similar to those observed among Mexican men in the HIM Study.

Four HPV studies among U.S. men have been published to date, with a reported range in HPV prevalence of $28.2 \%$ (where limited sampling and genotyping was conducted) to $42-45.5 \% .^{18,24-26}$ The latter U.S. studies included men residing in Hawaii, ${ }^{24}$ Seattle, ${ }^{25}$ and Arizona ${ }^{18}$ and utilized sampling and genotyping methods similar to those reported in the current study. Among community men residing in Arizona and Florida who were sampled at both external genital sites and anal canal, HPV prevalence was $51.2 \%$ and another $14.3 \%$ were infected with unclassified infections. ${ }^{18}$ Prevalence of HPV types $6,11,16$, and 18 was $4.8 \%, 0.4 \%, 11.4 \%, 1.9 \%$. In a small cross-sectional study conducted in Hawaii, approximately $2.5 \%, 1.5 \%, 6.5 \%$, and $3.0 \%$ were positive for HPV types 6, 11, 16, and 18, respectively, values similar to those reported in the HIM Study ${ }^{24}$ Collectively it appears that HPV infection in men is common and consistently high among men in different regions of the U.S. and the Americas. HPV type distribution appears to vary by population included within countries as well across countries.

A relatively high proportion of unclassified infections was observed (10-20\%) in the HIM Study cohort, similar to other reports. ${ }^{18,22,27,28}$ With the Linear Array HPV genotyping test used in this study it was possible to detect $37 \mathrm{HPV}$ types. However, due to the large number of HPV types that infect human epithelium, this assay is unable to characterize a portion ( $14.7 \%$ in this study) of the infections detected on PCR. We recently reported a similar prevalence of unclassified HPV infections detected in the external genital epithelium of U.S. men. ${ }^{18}$ Likewise, among studies that have tested for at least 20 HPV types in male genital skin, the range of unclassified HPV types reported is between 1.8-11.6\%., ${ }^{62,26-28}$ The significance of the unclassified infections is not known. This may represent infection with HPV types other than the 37 that are included in the linear array assay of Roche, or this may represent non-specific amplification of gene 
Age distribution of Oncogenic HPV infections $(p=0.00 \mathrm{I})$

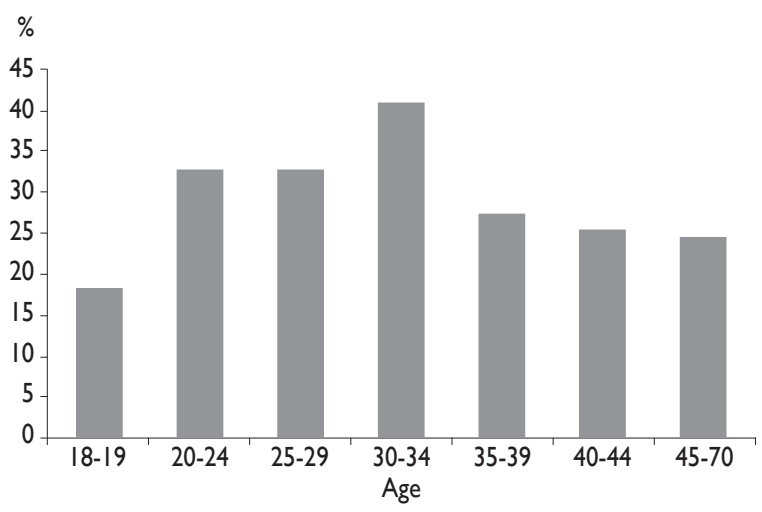

Age distribution of Unclassified HPV infections $(p=0.00 \mathrm{I})$

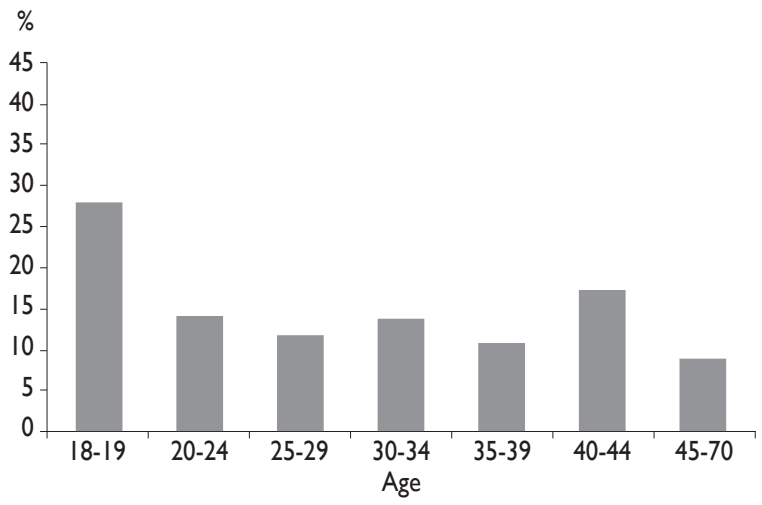

Age distribution of Non-oncogenic only HPV infections $(p=0.002)$

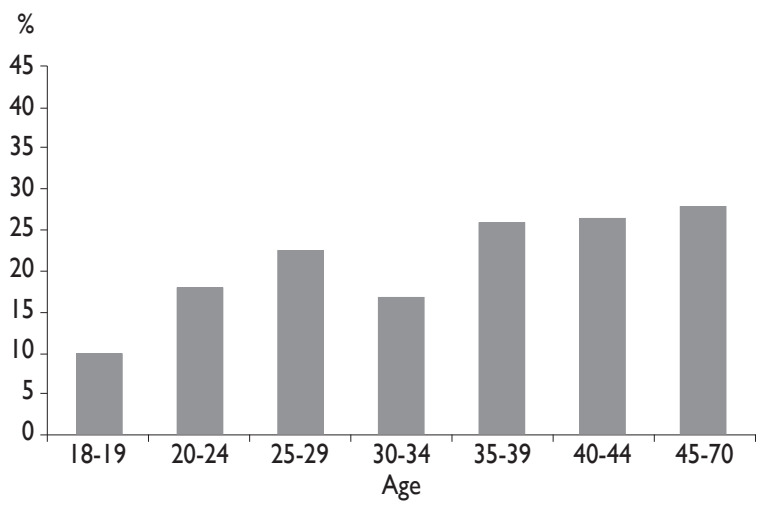

Note: add indication of statistical significance to legend and bar graph

Figure I: HPV PREVALENCE AT ENROLLMENT by AGE: A) ANY ONCOGENIC HPV INFECTION; B) NON-ONCOGENIC HPV INFECTION ONLY; C) UNCLASSIFIEd INFECTIONS. AlL three CATEGORIES OF HPV INFECTION SHOWED SIGNIFICANT DIFFERENCES BY AGE GROUP $(P<0.005)$ sequences that are not HPV related. As HPV type distribution appears to differ in men compared to women, it is important to characterize the HPV types that comprise this "unclassified" group. Results from direct sequencing of the gene products of PCR of the specimens included in this study indicate the presence of HPV types 2, 3, 12, 17, $22,23,74,87,91$, and 107 , types not currently included in the linear array assay. Bleeker and colleagues, ${ }^{27}$ sequenced "unclassified" specimens and found six additional HPV types (HPV types 3, 10, 32, 34, 86, and jc9710) that are not included in the linear array assay, accounting for between 0.8 and $3.8 \%$ of the HPV positive results. Studies of anal HPV infection among men who have sex with men have also reported the presence of HPV types that are not included in the linear array genotyping detection system utilized in the current study. These types include HPV 2, 13, 34, and 57, ${ }^{29}$ and Pap 155, Pap 291, and AE2. ${ }^{30}$ Understanding the significance of these HPV types requires additional study.

Overall, the prevalence of any HPV among men enrolled in the HIM Study was not associated with age. However, differing patterns of age association were observed depending on the category of HPV infection assessed. For example, a linear increase in non-oncogenic infections with age was observed, a bi-modal distribution with age was observed for oncogenic infections such that the younger and older males had the lowest prevalence of HPV. In contrast to these two patterns, a significant linear decrease in unclassified infections was observed with age. Among men participating in a small cross-sectional study in Mexico HPV prevalence was lower in the youngest age group ( $<20$ years); however, these differences did not reach statistical significance. ${ }^{22}$ In contrast to this, risk of HPV acquisition appeared to be higher in the younger age group in a small prospective study conducted in Mexico. ${ }^{21}$ Among studies conducted in the U.S., no association with age was observed. ${ }^{18,26}$ In a cross-sectional study conducted in Denmark an inverse association with age was observed. ${ }^{31}$ These data illustrate the complexity of HPV infection in men and highlight the need for prospective data that can distinguish differences in incidence and duration of infection by age in men.

As with any study there are limitations that influence the interpretation of results. By recruiting men from a variety of sources in the community we have attempted to enroll a representative population of men for study. However, as with any study, men who are interested and committed actually enrolled to the study, reducing the generalizability of the study findings. In addition, recruitment of study participants occurs in only one metropolitan area per country. Therefore, results do not represent the country as a whole. Study 
entry criteria that excluded men with active STIs were intended to decrease the likelihood of overestimating HPV prevalence. However, men who are interested in study participation may have had a sexual partner with HPV related lesions thereby increasing their interest and likelihood of participation in the study. This may have increased observed HPV prevalence.

In conclusion, a high prevalence of HPV infections in men across the three countries evaluated, Brazil, Mexico, and the U.S. was observed. Differences in overall HPV prevalence and type specific prevalence between countries were observed. The relationship between age and HPV prevalence in men enrolled in the HIM Study varies by type of infection examined. Studies of HPV type distribution in other regions of the world, utilizing rigorous methods of sampling and sample analyses, are needed to further clarify HPV type distribution and age differences among men.

\section{Acknowledgments}

The authors would like to thank the following staff for their dedication in recruiting, examining, and maintaining cohort participants, as well conducting HPV DNA laboratory analyses: Kathy Eyring, CCRP; Christine Gage, ARNP; Kayoko Kay; Pauline Schwalm-Andel; Rana Zaki, MPH, Sireesha Banduvula, MS, Kyle Wolf, Danelle Smith, MS, Steven McAnany, Shannon McCarthy, and the Tissue Core staff of the Moffitt Cancer Center for their help managing biological samples from the US site; B Fietzek, E Brito, F Cernicchiaro, F Silva, G Ribeiro, J Antunes, L Galan, R Bocalon, R Hessel, R Matsuo, R Otero, R Terreri, S Araujo, V Relvas, V Souza from the Brazil site; A Cruz, P Hernández, A Rodríguez-Cid, G Alvarez, O Rojas, DA Salazar, N Herrera, A Rodríguez, R Alvear - AL Landa and P Román from the Mexico site.

The authors would also like to thank the Digene Corporation for kindly providing STM for the collection and storage of samples at no charge to the study.

Funding Sources: This project was supported through a grant from the National Cancer Institute, National Institutes of Health, CA\#. RO1CA098803. Publication and report contents are solely the responsibility of the authors and do not necessarily represent the official views of NCI/NIH. Dr. Nielson was supported by NCI grant R25 CA078447.

Conflicts of interest: Presented in part: $23^{\text {rd }}$ International Papillomavirus Conference and Clinical Workshop, September 2006, Prague, Czech Republic, Abstract \# P- PS 26-3.

\section{References}

I.Agarwal SS, Sehgal A, Sardana S, Kumar A, Luthra UK. Role of male behavior in cervical carcinogenesis among women with one lifetime sexual partner. Cancer 1993;72:1666-1669.

2. Buckley JD, Harris RW, Doll R, Vessey MP, Williams PT. Case-control study of the husbands of women with dysplasia or carcinoma of the cervix uteri. Lancet I981;2:1010-1015.

3.Thomas DB, Ray RM, Pardthaisong T, Chutivangse S, Koetsawang S, Silpisornkosol S, et al. Prostitution, condom use, and invasive squamous cell cervical cancer in Thailand.Am J Epidemiol 1996;143:779-786. 4. Zunzunegui MV, King MC, Coria CF, Charlet J. Male influences on cervical cancer risk. Am J Epidemiol 1986; 123:302-307.

5. Bosch FX, Castellsague X, Munoz N, De SDanjosé S, Ghaffari AM, González LC. Meijer CU, Shah KV, De Sanjosé S, et al. Male sexual behavior and human papillomavirus DNA: key risk factors for cervical cancer in Spain. J Natl Cancer Inst 1996;88:1060-1067.

6. Castellsague X, Bosch FX, Munoz N, et al. Male circumcision, penile human papillomavirus infection, and cervical cancer in female partners. $\mathrm{N}$ Engl J Med 1996;346: I I05-III2.

7. Shah KV. Human papillomaviruses and anogenital cancers. N Engl J Med 1997;337:1386-1388.

8. Giuliano AR, Salmon D. The Case for a Gender Neutral (Universal) HPV Vaccination Policy in the US. Cancer Epidemiol Biomarkers Prev. 2008;(4):805-808.

9. Dunne EF, Nielson CM, Stone KM, Markowitz LE, Giuliano AR. Prevalence of HPV infection among men:A systematic review of the literature.J Infect Dis 2006; 194:1044-1057.

10. Clifford GM, Smith JS, Aguado T, Franceschi S. Comparison of HPV type distribution in high-grade cervical lesions and cervical cancer: a metaanalysis. Br J Cancer 2003;89:10I-I05.

II. Flores R,Abalos TA, Nielson CM, Abrahamsen M, Harris RB, Giuliano AR. Reliability of sample collection and laboratory testing for HPV Detection in Men.JVirol Methods 2008; 149(I):I36-I43.

I2. Giuliano AR, Nielson CM, Flores R, Dunne EF, Abrahamsen M,

Papenfuss MR, et al.The optimal anatomic sites for sampling heterosexual men for human papillomavirus (HPV) detection: the HPV detection in men study.J Infect Dis 2007; 196: I I46-I I 52.

13. Gravitt PE, Peyton CL, Alessi TQ,Wheeler CM, Coutlee F, Hildesheim A, et al. Improved amplification of genital human papillomaviruses. Journal of Clinical Microbiology 2000;38:357-36I.

14. Gravitt PE, Peyton CL, Apple RJ, Wheeler CM. Genotyping of 27 human papillomavirus types by using $\mathrm{LI}$ consensus PCR products by a single-hybridization, reverse line blot detection method. Journal of Clinical Microbiology 1998;36:3020-3027.

I5. Cogliano V, Baan R, Straif K, Grosse Y, Secretan B, El Ghissassa F, et al. Carcinogenicity of human papillomaviruses. Lancet Oncology 2005;6:204. 16. de Roda Husman AM,Walboomers JM, van den Brule AJ, Meijer CJ, Snijders PJ.The use of general primers GP5 and GP6 elongated at their 3' ends with adjacent highly conserved sequences improves human papillomavirus detection by PCR. J Gen Virol 1995;76(Pt 4): I057-I062. 17. Holm S. A Simple Sequentially Rejective Bonferroni Test Procedure. Scandinavian Journal of Statistics 1979;6:65-70.

18. Nielson CM, Flores R, Harris RB,Abrahamsen M, Papenfuss MR, Dunne EF, et al. Human papillomavirus prevalence and type distribution in male anogenital sites and semen. Cancer Epidemiol Biomarkers Prev. 2007; |6:II07-III4.

19. Rombaldi RL, Serafini EP,Villa LL,Vanni AC, Barea F, Frassini R, et al. Infection with human papillomaviruses of sexual partners of women having cervical intraepithelial neoplasia. Braz J Med Biol Res. 2006;39:177-87. 
20. Franceschi S, Castellsague X, Dal Maso L, Smith JS, Plummer M, Ngelangel $C$, et al. Prevalence and determinants of human papillomavirus genital infection in men. $\mathrm{Br}$ J Cancer 2002;86:705-7I I.

21. Lajous M, Mueller N, Cruz-Valdez A, Aguilar LV, Franceschi, S, Hernández-Avila M, et al. Determinants of prevalence, acquisition, and persistence of human papillomavirus in healthy Mexican military men. Cancer Epidemiol Biomarkers Prev 2005; 14:1710-1716.

22. Lazcano-Ponce E, Herrero R, Munoz N, Hernández-Avila M, Salmeron J, Leyva A, et al. High prevalence of human papillomavirus infection in Mexican males: comparative study of penile-urethral swabs and urine samples. Sex Transm Dis 200 I;28:277-280.

23.Vaccarella S, Lazcano-Ponce E, Castro-Garduno JA, Valdez A, Díaz V, Schiavon R, et al. Prevalence and determinants of human papillomavirus infection in men attending vasectomy clinics in Mexico. Int J Cancer 2006:1 19:1934-1939.

24. Hernandez BY, Goodman MT, Wilkens LR, Thompson P, Zhu X, Wons W, et al. Comparison of physician- and self-collected genital specimens for detection of human papillomavirus in men.J Clin Microbiol 2006;44:5।3-517. 25. Weaver BA, Holmes KK, Kiviat N, Lee SK, Meyer C, Stern M, et al. Evaluation of genital sites and sampling techniques for detection of human papillomavirus DNA in men.J Infect Dis 2004;189:677-685.

26. Baldwin SB,Wallace DR, Papenfuss MR, Abrahamsen M,Vaught LC,
Giuliano AR. Condom use and other factors affecting penile human papillomavirus detection in men attending a sexually transmitted disease clinic. Sex Transm Dis 2004;31:601-607.

27. Bleeker MC, Hogewoning C, Berkhof J,Voorhorst FJ, Hesselink AT, van Diemen PM, et al. Concordance of specific human papillomavirus types in sex partners is more prevalent than would be expected by chance and is associated with increased viral loads. Clin Infect Dis 2005;4I:6I 2-620. 28. Shin HR, Vaccarella S, Roh JW, Ju YH, Oh JK, Kong HJ, et al. Prevalence and determinants of genital infection with papillomavirus, in female and male university students in Busan, South Korea.J Infect Dis 2004; 190:468-476. 29. Palefsky JM, Holly EA, Ralston ML, Jay N. Prevalence and risk factors for human papillomavirus infection of the anal canal in human immunodeficiency virus (HIV)-positive and HIV-negative homosexual men. J Infect Dis 1998; 177:36I-367.

30. Piketty C, Darragh TM, Da Costa M, Bruneval P, Heard I, Kazatchkine $M D$, et al. High prevalence of anal human papillomavirus infection and anal cancer precursors among HIV-infected persons in the absence of anal intercourse. Ann Intern Med 2003; 138:453-459.

3I. Svare El, Kjaer S, Worm AM, Osterlind A, Meijer CJ, van den Brule AJ. Risk factors for genital HPV DNA in men resemble those found in women: a study of male attendees at a Danish STD clinic. Sex Transm Infect 2002;78:215-218. 